UDC 544.022.341, 544.022.382

\title{
FUSION-FISSION HYBRID SYSTEM DEVELOPMENT AND INTEGRATION INTO RUSSIA'S NUCLEAR POWER ENGINEERING
}

\author{
B.V. Kuteev ${ }^{l}$, Yu.S. Shpanskiy ${ }^{1,2}$ and DEMO-FNS Team ${ }^{3}$ \\ ${ }^{I} N R C$ «Kurchatov Institute», Moscow, Russia \\ ${ }^{2}$ National Research University, Moscow Power Engineering Institute, Moscow, Russia \\ Combining nuclear fusion and fission reactions in a single design offers the possibility of implementing nuclear energy systems with \\ qualitatively new characteristics and properties. Development of the fusion-fission hybrid facility based on the superconducting tokamak \\ DEMO-FNS is underway in Russia to allow steady-state fusion and nuclear technologies to be operated simultaneously and produce vel \\ up to $40 \mathrm{MW}$ of fusion power and about $400 \mathrm{MW}$ of fission power. Such a facility could provide burning the minor actinides accumulat- \\ ed by the Russian nuclear fuel cycle during the operation of nuclear power plants earlier and in the future. This paper presents an over- \\ view of the latest achievements in the area of the DEMO-FNS design and describes different operation scenarios for this facility. Related \\ research activities are part of ongoing Russia's Nuclear Energy Research Program
}

Key words: fusion and fission reactions, hybrid facility, superconducting tokamak, minor actinides, vacuum vessel, hybrid fuel cycle.

DOI: $10.21517 / 0202-3822-2021-44-2-7-14$

\section{РАЗВИТИЕ ГИБРИДНЫХ СИСТЕМ «СИНТЕЗ-ДЕЛЕНИЕ» И ИХ ИНТЕГРАЦИЯ В ЯДЕРНУЮ ЭНЕРГЕТИКУ РОССИИ}

\author{
Б.В. Кутеев ${ }^{1}$ Ю.С. Шпанский ${ }^{1,2}$ и команда DEMO-FNS \\ ${ }^{1}$ НИЦ «Курчатовский институт», Москва, Россия \\ ${ }^{2}$ Национальный исследовательский университет «Московский энергетический институт», Москва, Россия
}

\begin{abstract}
Наличие реакций ядерного синтеза и деления в одной установке позволит достичь принципиально новых характеристик и свойств ядерной энергетической системы. В России продолжается разработка гибридной установки термоядерного синтеза на основе сверхпроводящего токамака для комплексного использования стационарных и ядерных технологий мощностью до 40 МВт для термоядерного синтеза и 400 МВт для реакций деления. В дальнейшем эта гибридная система может быть интегрирована в ядерную систему России для пережигания (трансмутации) минорных актинидов в отработавшем ядерном топливе ядерных энергетических реакторов. Такая установка могла бы обеспечить сжигание минорных актинидов, накопленных российским ядерным топливным циклом в процессе эксплуатации атомных электростанций в настоящем и будущем. В данной статье представлен обзор последних достижений в области проектирования демонстрационного ТИН и описаны различные сценарии эксплуатации этой установки. Научно-исследовательская работа, проводимая в рамках этой проблемы, является частью Российской программы исследований в области ядерной энергетики.
\end{abstract}

Ключевые слова: реакции синтеза и деления, гибридная установка «синтез-деление», сверхпроводящий токамак, минорные актиниды, вакуумная камера, гибридный топливный цикл.

\section{INTRODUCTION}

At present, Russia's nuclear industry is shifting to the closed fuel cycle with an emphasis on thermal and fast power reactors. This calls for new spent fuel and radioactive waste management/incineration technologies, as well as the development of «fusion-fission» hybrid systems. Combining fusion and fission processes in one design offers the possibility of implementing nuclear energy systems with qualitatively new characteristics and properties A project is underway in Russia to develop a fusion-fission hybrid facility based on the DEMO-FNS superconducting tokamak to allow steady-state fusion and nuclear technologies to be operated simultaneously

${ }^{3}$ S.S. Ananiev, A.A. Glebova, A.V. Golubeva, E.D. Dlougach, D.N. Demidov, A.Yu. Dnestrovskij, B.V. Ivanov, A.V. Klischenko, B.N. Kolbasov, A.S. Kukushkin, V.E. Lukash, V.V. Lukianov, S.Yu. Medvedev, A.A. Morozov, A.Yu. Pashkov, V.S. Petrov, A.B. Sivak, A.V. Spitsyn, R.R. Khairutdinov, V.I. Khripunov, M.N. Shlenskiy, A.V. Zhirkin (NRC «Kurchatov Institute», Moscow, Russia); E.N. Bondarchuk, A.A. Voronova, E.R. Zapretilina, A.A. Kavin, S.V. Krasnov, A.N. Labusov, A.B. Mineev, V.P. Muratov, I.Yu. Rodin, V.A. Trofimov, M.V. Khohlov (Efremov Institute, St. Petersburg, Russia); I.V. Danilov, A.V. Lopatkin, I.B. Lukasevitch, V.E. Popov, Yu.S. Strebkov, A.G. Sysoev (NIKIET, Moscow, Russia); V.Yu. Sergeev, P.R. Goncharov, A.V. Skokov (St. Petersburg University (SPbPU), St. Petersburg, Russia). 
and produce up to $40 \mathrm{MW}$ (more than $10^{19}$ neutrons per second) of fusion power and $400 \mathrm{MW}$ of fission power This research is part of Russia's Nuclear Energy Research Program.

The project aims at achieving a steady-state operation with a $14 \mathrm{MeV}$-neutron wall loading of $\sim 0.2 \mathrm{MW} / \mathrm{m}^{2}$, and a life-cycle neutron fluence of $\sim 2 \mathrm{MW} \cdot y e a r / \mathrm{m}^{2}$. In addition, the blanket's plasma-facing surface should be $\sim 100 \mathrm{~m}^{2}$, i.e. large enough to enable the testing of materials and components in the energy spectrum of DT-thermonuclear neutrons, to conduct transmutation studies, generate energy and produce fission fuel nuclides and tritium.

The analysis of the interaction of the DEMO-FNS facility and further industrial options with the nuclear fuel cycle is carried out. Going forward, the discussed hybrid system could be integrated with Russian nuclear power plants to allow the burnup of minor actinides accumulated by the country's nuclear fuel cycle facilities. Under a closed fuel cycle, spent fuel, enriched in an industrial hybrid facility, goes back to the cycle, reducing the need for storage facilities and bringing down overall radiotoxicity. This paper presents the latest achievements in the area of the DEMO-FNS design (2019-2020) and describes different operation scenarios for this facility. The DEMO-FNS tokamak has the following key characteristics:

$\begin{array}{ll}\text { plasma current } I_{\mathrm{P}}, \mathrm{MA} \ldots & 5 \\ \text { major radius } R_{0}, \mathrm{~m} \ldots & 3.2 \\ \text { minor radius } a, \mathrm{~m} \ldots & 1.0 \\ \text { aspect ratio } R / a \ldots & 3.2 \\ \text { plasma elongation } k_{x} / k_{95} \ldots & 2.0 / 1.9 \\ \text { triangularity, } x \ldots & 0.2-0.5 \\ \text { Power parameters: } & \\ \text { D-T-fusion power, MW ... } & 40 \\ \text { fission power, MW ... } & 400 \\ \text { electric power, MW ... } & 200 \\ \text { total power, MW . . } & 700\end{array}$

Auxiliary heating power $P_{\text {aux }}=36 \mathrm{MW}$, including $30 \mathrm{MW}$ of neutral beam power and $6 \mathrm{MW}$ of ECR heating power (at $170 \mathrm{GHz}$ ). The DEMO plant is expected to help accomplish the following tasks:

- comprehensive testing of systems and technologies enabling the FNS steady-state operation, including hybrid blankets, electric power generation system and radiochemical equipment;

— testing of the prototypes of FNS hybrid breeder blankets (based on steady-state and molten salt technologies);

— scientific and technical support of pilot and industrial hybrid plants.

\section{DEMO-FNS DESIGN}

DEMO-FNS general layout is presented in Fig. 1.

DEMO-FNS is a complex facility that includes a superconducting magnetic system, a vacuum chamber, a hybrid blanket located in it (consists of six modules), and two (upper and lower) divertor units. The blanket module includes: the module body, an active core with a transmutation capability, a blanket breeder zone, and

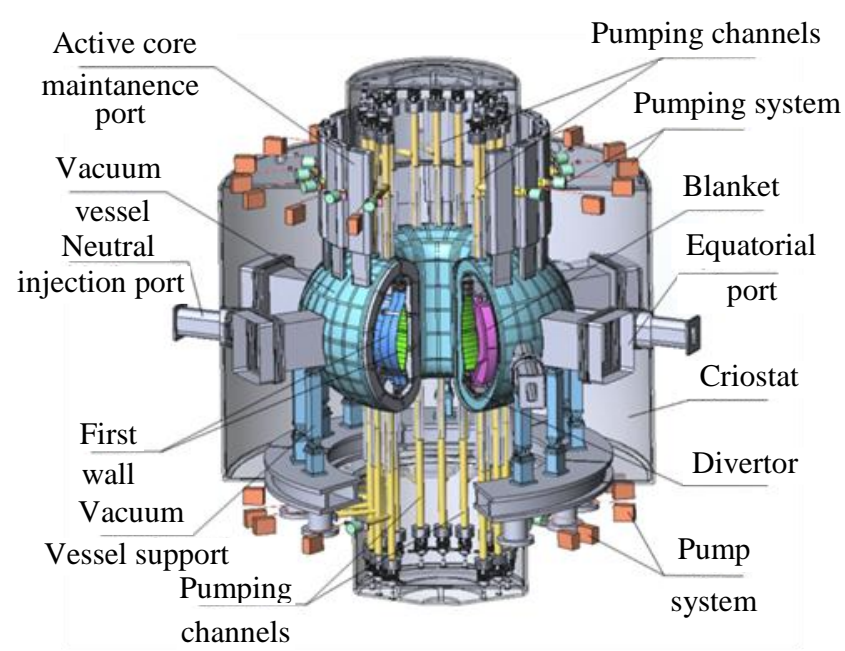

Fig. 1. DEMO-FNS device key design features (magnetic system not shown) coolant collectors.

Magnetic system. In accordance with the design principles, the magnetic system (MC) for the DEMOFNS must ensure a reliable operation of the system with a hybrid blanket and the corresponding hybrid nuclear fuel cycle. The DEMO-FNS's superconducting magnetic system includes: 18 toroidal field coils (TFCs); 6 sectioned central solenoid units); 4 pairs of poloidal field coils (PFCs); 18 correction coils arranged in 3 groups; 2 vertical control coils; current leads fabricated of high temperature superconductors. Materials used in toroidal and poloidal coils include: $\mathrm{Nb}_{3} \mathrm{Sn}, \mathrm{NbTi}$; $\mathrm{SS}$, Cu-alloys; polyimide insulator; Hecoolant. The MS and vacuum vessel configuration accommodates up to 18 vertically loaded hybrid blanket 
active cores and allows them to be retrieved for remote maintenance, which takes place in a designated area. Analyses of the electromagnetic forces and the stress analyses of DEMO-FNS MS were carried out. TFCs were found to be experiencing the heaviest stresses. After considering different options, an ITERlike design was chosen as optimal for the TFCs. View of the toroidal coil and its finite elements mesh is shown in Fig. 2.

A stress-strain analysis of the coils revealed that the proposed coil design meets the static strength criteria (Fig. 3)

Vacuum vessel. The vacuum vessel (VV) is an all-welded two-layer toroidal shell (Fig. 4) inside the magnetic system. The space between the inner and outer shells is filled with water and steel plates (an iron-water shielding) to provide adequate neutron protection. The VV has the following main components (see Fig. 1):

- body;

- equatorial ports, which provide access inside the vessel for remote handling and maintenance operations and plasma diagnostics;

— injection ports for introducing neutral particles into plasma;

- pipes for vacuum pumping;

— support structure that bears the VV's weight and protects
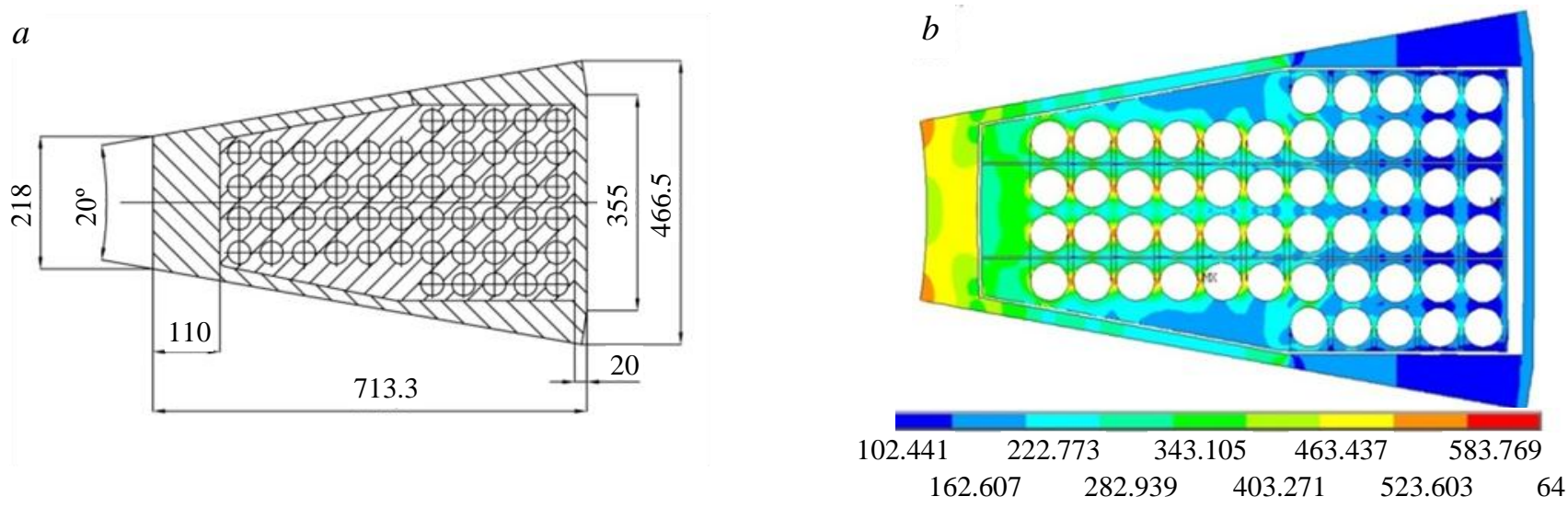

Fig. 3. Cross-section dimensions ( $a$ ) and equivalent stresses (MPa) of the toroidal coil $(b)$

it from electromagnetic loads;

- support system for steadying the divertor, blanket, turns of passive and active plasma stabilization, first wall elements and other in-vessel components;

- collectors of water cooling the VV and its internal components.

The VV wall inner shell is $0.72 \mathrm{~m}$ thick (this helps reduce volumetric heat deposition in the TFC superconductor materials), and the outer shell has a thickness of $0.60 \mathrm{~m}$. At this stage of the design development, the VV was considered, adapted for a hybrid blanket with a steady-state breeding zone and a reloadable active core containing fuel assemblies with minor actinides.

Vertical ports for reloading the blanket active core are in the VV upper part. Each sector has three rectan-

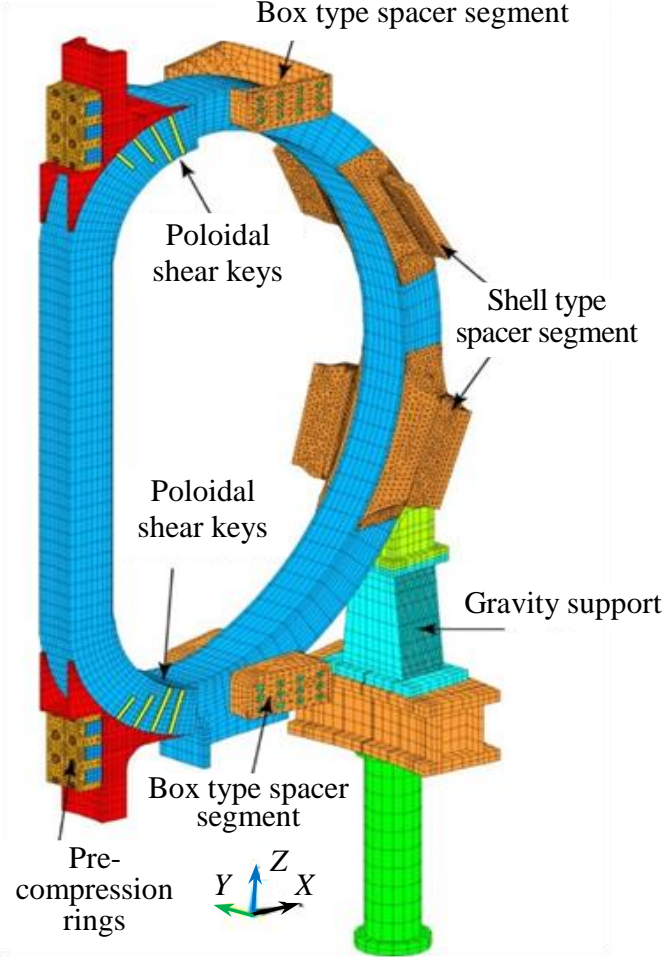

Fig. 2. View of a toroidal coil modeled with a finite element mesh

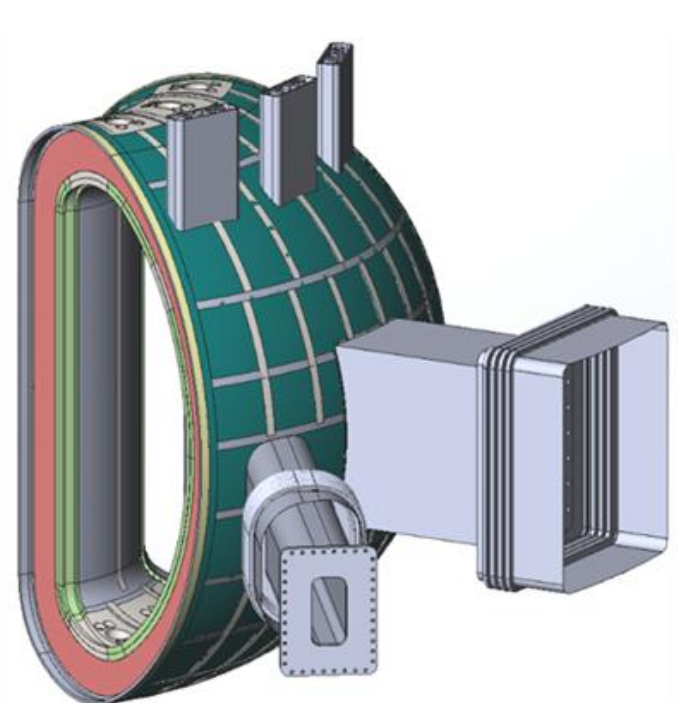

Fig. 4. VV general layout 
gular branch pipes making the total number of branch pipes in the FNS facility 18 . With the existing arrangement of the blanket core reloading ports, exhaust tubes, cooling water outlet channels, the installation of mounting welded joints of the vacuum vessel sectors is possible only under the toroidal field coils. Two supports are provided for the VV installation on each sector. One is located beneath the equatorial port at the junction with the outer shell of the vacuum vessel, the other is beneath the pipe used for injecting neutral particles. At the top and at the bottom, the supports are equipped with articulated joints that allow the vessel to move freely in the radial direction, compensating for the change in its dimensions at various operating temperatures. The supports in the lower part rest on supports, which are installed on a base common with the magnetic system. Dielectric inserts are provided between the supports and fittings that electrically insulate the VV supports from the common base. For convenience and in order to speed up on-site assembly operations, the vacuum vessel will be assembled of six 60-degree sectors.

Blanket. The DEMO-FNS's hybrid blanket consists of two parts, the active core (AC) and the breeding zone (BZ):

- the AC includes 12 full-size and 6 shortened units;

- the BZ, intended for reproduction of tritium, is placed on the outer bypass of the FNS VV for the entire operation life and is to be dismounted only in case of failure or emergency;

- reloading of the AC of the hybrid blanket of the FNS, the general view of which is shown in Fig. 1, is carried out through the vertical service channels at the stopped facility;

- BZ modules mounting/dismantling is carried out through six equatorial (horizontal) service ports of invessel components.

The AC structure, whose general arrangement is shown in Fig. 5, includes: body; cover of the AC case; eight fuel assemblies containing fuel elements with a mixture of minor actinides (MA); two flexible mechanical supports.

The AC of the hybrid blanket consists of 8 fuel assemblies assembled with fuel elements containing a mixture of MA in a metallic form. Each fuel assembly consists of 56 fuel rods. BZ cases, are mounted on the external bypass of the VV. Mounting / dismantling of the BZ cases is carried out through the equatorial port of the invessel components of the FNS facility. Structurally, BZ is a canister structures that occupy all the available space located between the rear surface of the AC case and the surface of the VV. The breeding zone includes modules of varous sizes. General view and volumes of BZ modules are shown in Fig. 6.

$\mathrm{BZ}$ modules are filled with lithium-containing ceramics - lithium orthosilicate $\mathrm{Li}_{4} \mathrm{SiO}_{4}$ in the spherical form with a volumetric filling of at least $60 \%$ and a granule diameter of $1-1.5 \mathrm{~mm}$. To accelerate the release of tritium and its subsequent removal of the BZ, a purge gas is pumped through the ceramics under a pressure of

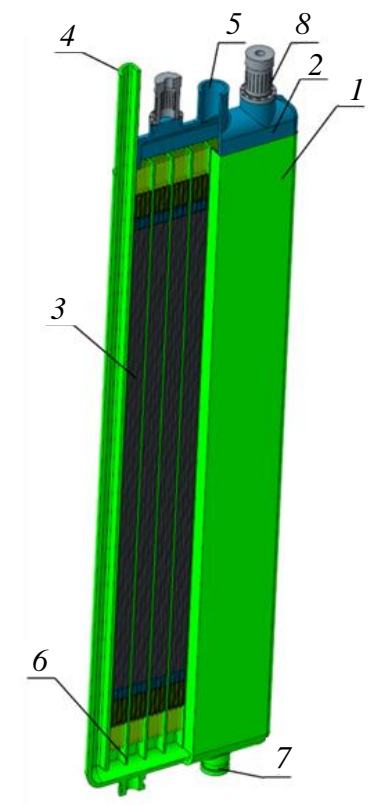

Fig. 5. General view of AC of DEMO-FNS hybrid blanket: $1-\mathrm{AC}$ case; 2 - cover of the AC case; 3 - fuel assembly with fuel rods from MA; 4 - inlet coolant pipe; 5 - outlet coolant branch pipe; 6 - inter-channel partition; 7 - the counterpart of the collet fastening of the $\mathrm{AC}$ to the $\mathrm{VV} ; 8$ - flexible mechanical supports

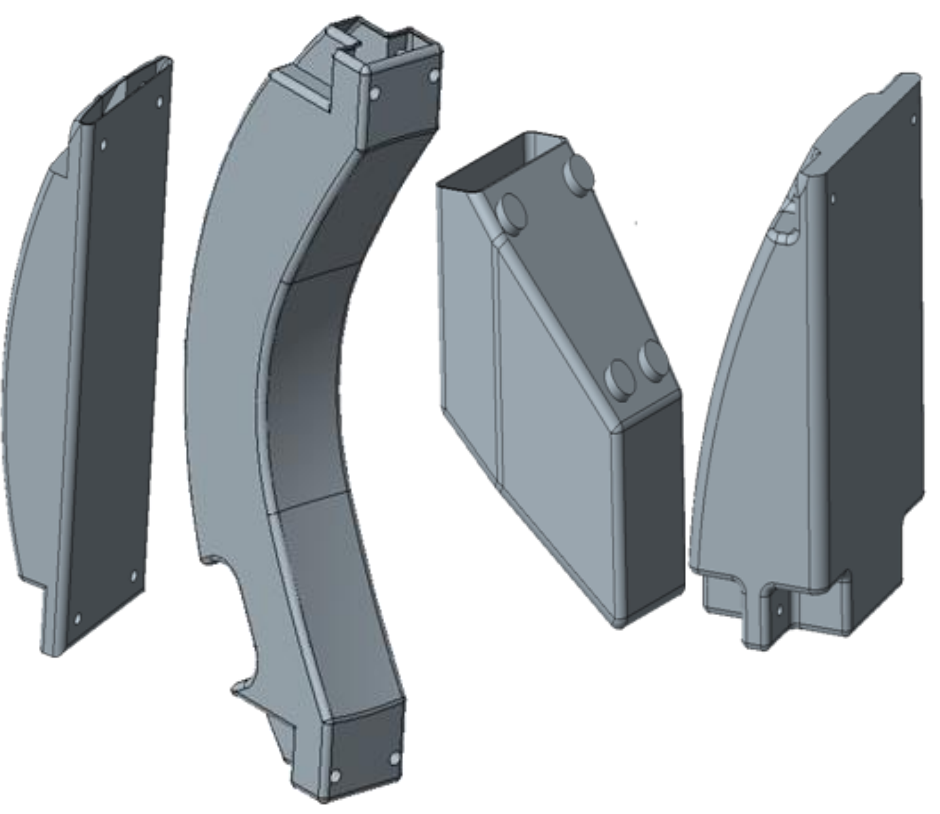

Fig. 6. General view of BZ blanket modules 
$0.15-0.2 \mathrm{MPa}$. Purge gas for tritium is helium with the addition of $1 \%$ hydrogen. Many coolants were consid cred during design development - liquid metal, water, water-steam mixture and supercritical $\mathrm{CO}_{2}\left(\mathrm{SCO}_{2}\right)$. Two last ones seem to be preferable due to hydrodynamics and neutron physics advantages.

Thermal scheme of energy conversion. It is assumed that DEMO-FNS facility will generate $200 \mathrm{MW}$ of electric power for its own needs. Electricity production is expected with efficiency of $40 \%$. Fig. 7 shows the thermal diagram of a two-circuit power conversion of DEMO-FNS facility with $\mathrm{SCO}_{2}$ cooling of active core (high temperature heating).

The first circuit includes a gas loop that cools AC 3 , a heat accumulator 5 , a steam generator 6 , a primary circuit coolant blower 17 , a bypass valve 18 . The second circuit includes steam generator 6 , turbo generator 7 , condenser 8 , condensate pump 9 , low pressure regenerative heaters 10 , deaerator 12 , feed pump 13 , high pressure regenerative heaters 14 . Low-grade heat generated by the first wall 1 and the lithiumcontaining breeding zone 2 is transferred to the regenerative heating system through the water-to-water 11 and gas-to-water 15 heat exchangers, respectively by the pump 19 and the blower 16. Low-temperature heat can be partially used for heating needs. In the $\mathrm{AC}$, heat is generated at a coolant temperature of up to $500{ }^{\circ} \mathrm{C}$. The high-temperature heat of the gaseous coolant is effectively converted into electricity according to the conventional scheme of a two-circuit nuclear power plant using a steam generator and a

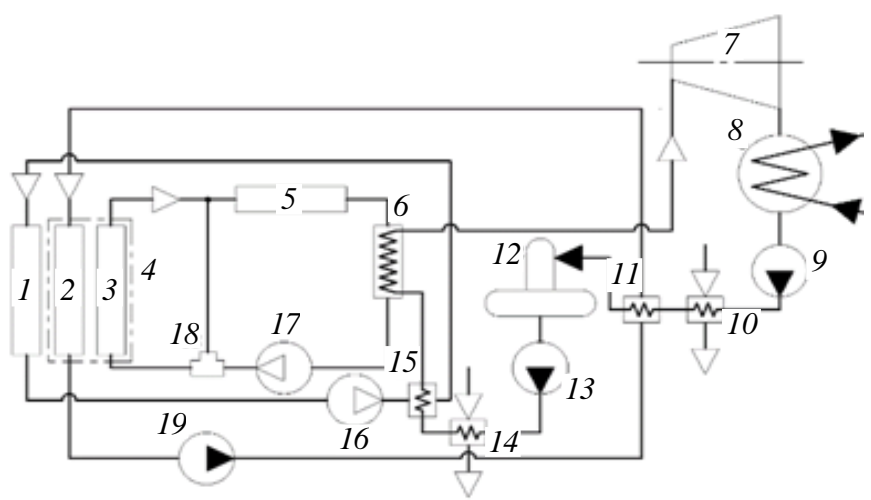

Fig. 7. Thermal diagram of a two-circuit hybrid facility: 1 - first wall; 2 - breeding zone; 3 - active core; 4 - blanket; 5 - heat accumulator; 6 - steam generator; 7 - steam turbine; 8 - condenser; 9 - condensate pump; 10 - regenerative low pressure heaters; 11 - water-to-water heat exchanger; 12 - deaerator; 13 - feed pump; 14 - high pressure regenerative heaters; 15 gas-water heat exchanger; 16 - first wall coolant blower; 17 active core coolant blower; 18 - bypass valve; 19 - circulation pump of the lithium-containing zone cooling turbine. In order to prevent the equipment from being subjected to $100 \%$ load surges, a heat accumulator is included in the thermal circuit of the facility. It is charged with excess heat during the working part of the cycle and transfers the accumulated heat to the coolant during a pause, compensating for the power failure. One of the types of heat storage devices are phase change batteries. They are based on the phenomenon of melting and crystallization of an accumulating substance, accompanied by absorption or release of latent heat of the phase transition.

MA composition. It is assumed that in the implementation of FNS with a hybrid blanket, the materials loaded by MA will have an exposure time of 10 to 50 years. The starting fuel composition corresponds to the MA composition obtained by 2050 after reprocessing spent nuclear fuel from thermal reactors within the framework of calculating the scenario of the development of nuclear power in the Russian Federation in a system of thermal reactors with a maximum achievable power of $28.5 \mathrm{GW}$. The composition of MA considered in the calculation is presented in Table.

Composition of MA mixture, from accumulated SNF by 2050

\begin{tabular}{c|c}
\hline Nuclide & Mass fraction, \% \\
\hline${ }^{237} \mathrm{~Np}$ & 30.0 \\
${ }^{241} \mathrm{Am}$ & 65.0 \\
${ }^{242 m} \mathrm{Am}$ & 0.06 \\
${ }^{243} \mathrm{Am}$ & 4.5 \\
${ }^{243} \mathrm{Cm}$ & 0.02 \\
${ }^{244} \mathrm{Cm}$ & 0.42 \\
\hline
\end{tabular}

\section{INTEGRATION OF FFHS IN RUSSIAN NUCLEAR POWER ENGINEERING}

The universal system model of nuclear power in Russia was chosen as an analysis tool. This tool was developed at JSC NIKIET under the leadership of E.V. Muraviev. The model is embedded in the USM-1 software product («Universal System Model-1» [4]) and contains the history of nuclear power in Russia and forecasts for 
the future period to 2130. This program allows working with a large number of information collected on all operating, as well as commissioned, power plants and provides the ability to extrapolate data up to 2130 .

In this work assessment was carried out of the impact the fusion neutron sources operation on the amount of MA in the nuclear power system, taking into account the capabilities of the fuel cycle enterprises for spent nuclear fuel (SNF) reprocessing and fuel fabrication. The following assumptions were taken into account:

— an optimistic and moderate scenario for the development of nuclear power was considered;

- modeling takes into account export of nuclear power plants and reprocessing of the SNF returned;

— SNF reprocessing - centralized and on-site;

- modeling is carried out assuming the two-component nuclear energy in Russian Federation;

- the roadmap of the project at the moment provides for the creation of three facilities in the interval from 2033 to 2055:

- DEMO-FNS (year 2033) - loading $100 \mathrm{t}$ U, $20 \mathrm{t}$ MA. Duty factor $(\mathrm{DF})=0.3$; thermal power $500 \mathrm{MW}$;

- pilot FNS (year 2045) - loading: 100 t U, 20 t MA. DF = 0.8, thermal power $500 \mathrm{MW}$;

— industrial FNS (year 2055) - loading $150 \mathrm{t}$ U, $40 \mathrm{t}$ MA. DF $=0.95$, thermal power $1365 \mathrm{MW}$.

The optimistic scenario for the development of nuclear power assumes the achievement of $115 \mathrm{GW}$ of the installed capacity of nuclear power plants in Russia and 177 GW taking into account the installed capacity of exported NPPs by 2130. The moderate scenario of the development of nuclear power assumes the achievement of $67 \mathrm{GW}$ of the installed capacity of nuclear power plants in Russia and $123 \mathrm{GW}$ taking into account the installed capacity of exported NPPs by 2130 . The results of the analyses are shown in Figs $8-11$.

Optimistic scenario of nuclear power development assumes SNF reprocessing enterprises will produce $472 \mathrm{t}$ of MA by 2130, of which $374 \mathrm{t}$ of MA will remain, taking into account the operation of the FNSs (Fig. 10), provided that blanket is fully loaded. Moderate scenario of nuclear power development, SNF reprocessing enterprises will produce $170 \mathrm{t}$ of MA by 2130, of which $72 \mathrm{t}$ of MA will remain, taking into account the operation of the FNSs, provided that blanket is fully loaded.

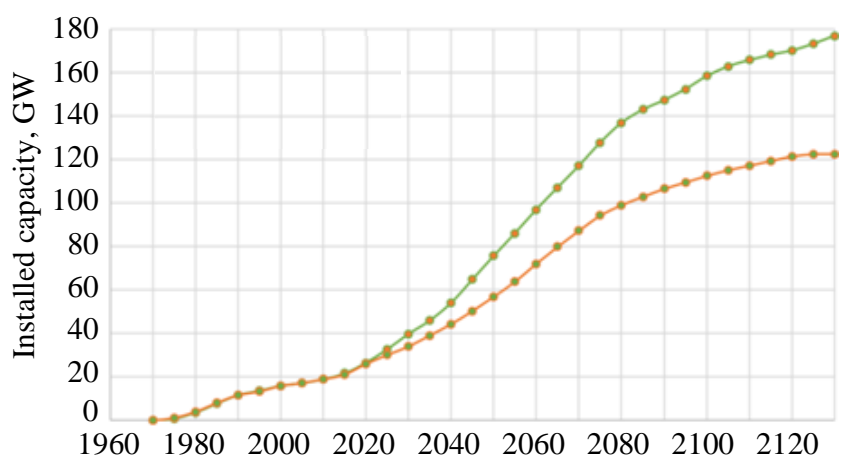

Fig. 8. Installed Power of nuclear power plants in Russia and export nuclear power: - - _ optimistic scenario; - - — moderate scenario

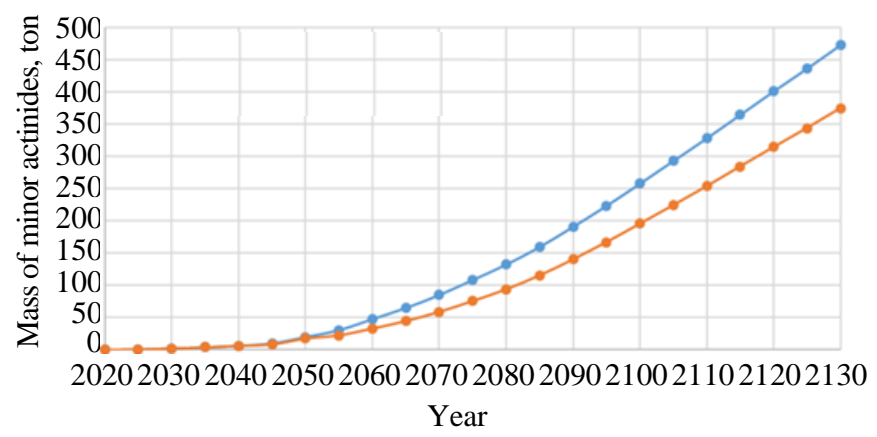

Fig. 10. Mass of allocated MA in the nuclear energy system of Russia (+export). Optimistic scenario: - - - extracted MA; - - left after all FNS work

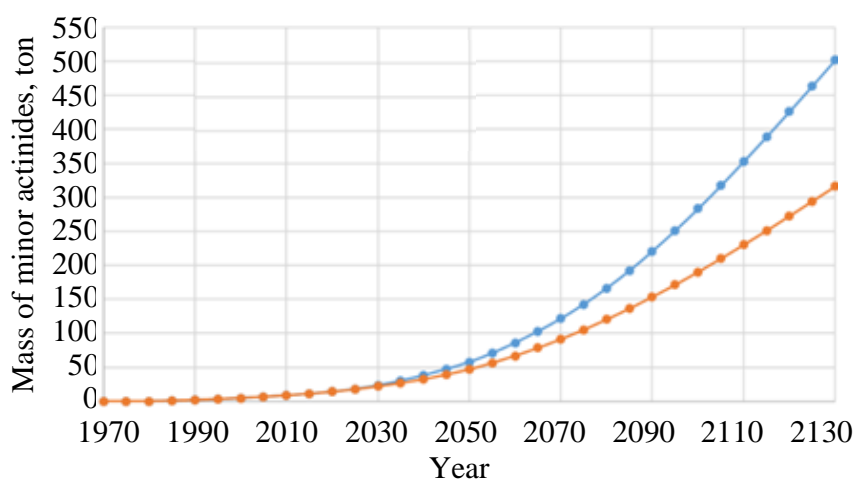

Fig. 9. Amount of accumulated IVIA in the nuclear energy system: $-\bullet-\ldots$ optimistic scenario; $-\bullet \_$_ moderate scenario

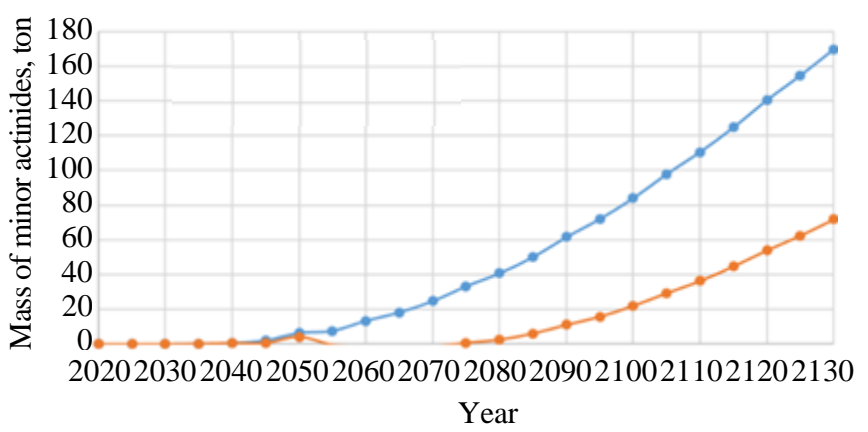

Fig. 11. Mass of allocated MA in the nuclear energy system of Russia (+export). Moderate scenario: -॰- — extracted MA; - - left after all FNS work 
From the results obtained, it can be assumed that 3-4 hybrid systems are able to ensure the balance of the produced and transmuted MA in the power system, provided that the necessary capacities for SNF reprocessing and fuel fabrication are provided. Evolution of specific activity for MA, fission products and decay products during and after single irradiation in DEMO-FNS (per $1 \mathrm{t}$ of initial fuel) was analyzed (Fig. 12).

The MA activity after irradiation remains slightly higher than that initial. MA total amount decreases. $906 \mathrm{kgs}$ from $26 \mathrm{t}$ of very active materials are transmuted into decay the activity of which decreases much faster. The rest of MA ceases to belong to the waste class and is included in the nuclear fuel cycle,

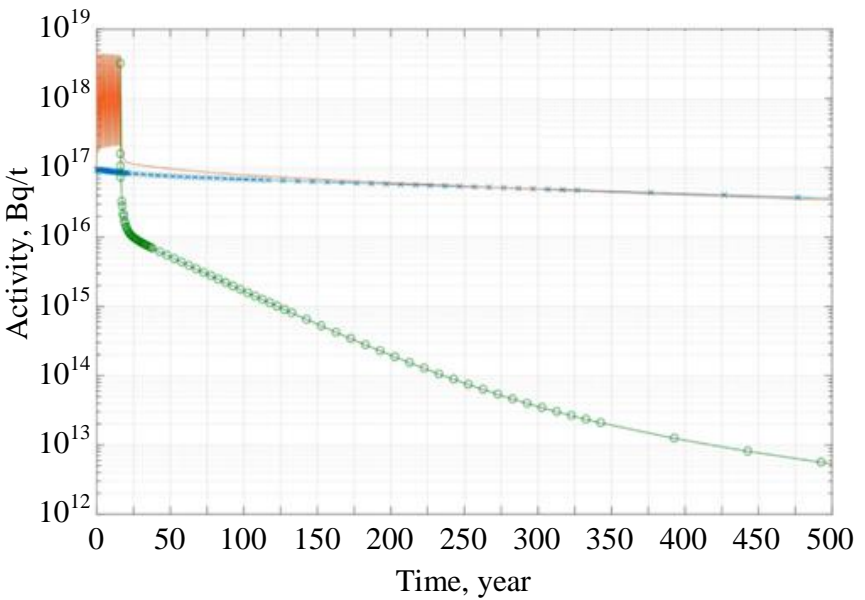

Fig. 12. Evolution of specific activity for MA, fission products and decay products during and after single irradiation in DEMOFNS: $-\boldsymbol{x}-$ - MA without irradiation; - - irradiated w/o processing; $-0-$ - fission and decay products after MA irradiation where it is gradually converted into fission products.

Organization of DEMO-FNS project development. At the beginning of 2021, the Russian government adopted a program for the development of fusion-fission hybrid systems. Scientific management was entrusted to NRC «Kurchatov Institute». The proposal of project management structure is the following.

\section{Project management structure (proposal):}

Project office - State corporation Rosatom;

Scientific management - NRC «Kurchatov Institute»;

General designer of tokamak - D.V. Efremov Institute of Electrophysical Apparatus;

General designer of blanket and fuel cycle - Dollezhal Institute of Power Engineering;

General Designer of Materials — Bochvar High-Technology Institute for Inorganic Materials;

General project designer — JSC Eleron;

Development of the divertor - Peter the Great St. Petersburg Polytechnic University;

Heat engineering and energy conversion - Joint Institute for High Temperature RAS + Moscow Power Engineering Institute + Budker Institute of Nuclear Physics, Siberian Branch of RAS; ;

Staffing - Ministry of Education + State corporation Rosatom (1200 people);

Regulator - Rostechnadzor.

\section{CONCLUSIONS}

Enabling systems of DEMO-FNS were upgraded including: vacuum vessel, radiation shield, divertor, blanket, fueling cycle, design activity was supported by R\&D in neutronics, optimization of the device layout, subsystems including MS, VV, divertor, blanket and T-fuel cycle. 3 to 4 Industrial FNS systems are capable of ensuring the equilibrium of the produced and transmuted MA in the RF nuclear power system, provided that the necessary capacities for SNF reprocessing and fuel fabrication are implemented.

\section{REFERENCES}

1. Kuteev B.V., Azizov E.A., Alexeev P.N., Ignatiev V.V., Subbotin S.A., Tsibulskiy V.F. Development of DEMO-FNS tokamak for fusion and hybrid technologies. - Nucl. Fusion, 2015, vol. 55, p, 073035 (8 p.).

2. Kuteev B.V., Shpanskiy Yu.S. and DEMO-FNS Team. Status of DEMO-FNS development. — Nucl. Fusion, 2017, vol. 57, p. 076039.

3. Shpanskiy Yu.S. and DEMO-FNS Team. Progress in the design of the DEMO-FNS hybrid facility. - Nucl. Fusion, 2019, vol. 59, p. 076014. 
4. Muraviev E. Generator of system models USM-1. - M.: FGUP Dollezhal RDIPE, 2008. 115 p.

5. Kuteev B.V., Goncharov P.R. Fusion-fission hybrid systems: yesterday, today, and tomorrow. - Fusion Science and Technology, 2020, vol. 76, p. 836 -847; DOI: https://doi.org/10.1080/15361055.2020.1817701.

\section{AUTHORS}

Boris V. Kuteev, Professor, Deputy Head Tokamak Department Fusion Research Centre; NRC «Kurchatov Institute», 1, Academika Kurchatova sq., Moscow, 123182, Russia, Kuteev_BV@ nrcki.ru

Yury Sergeevich Shpanskiy, Head of division, PhD Sci; NRC «Kurchatov Institute», 1, Academika Kurchatova sq., Moscow, 123182, Russia, Shpanskiy_YS@nrcki.ru

Received 15 January 2021

Revised 16 March 2021

Accepted 25 March 2021

Problems of Atomic Science and Technology Ser. Thermonuclear Fusion, 2021, vol. 44, issue 2, pp. 7-14 